\title{
Mechanism for the Forced Strengthening on the Diaphragm Spring's Load-Deflection Characteristic
}

\author{
Gong Yubing and Zhang Defeng
}

\begin{abstract}
Load-deflection characteristic of the diaphragm spring during its life time may vary, which usually leads to slipping, burns and other failures in industry application. To avoiding these failures, the forced strengthening process in manufacturing of the diaphragm spring is often applied to stabilize the load-deflection characteristic of the spring by accelerating its elastic extenuation before it goes out. However the mechanism for the forced strengthening process on the diaphragm spring load-deflection characteristic is not yet completely understood. Based on the finite element method, the model of the diaphragm spring was built and the forced strengthening process was simulated. The load-deflection characteristic before and after the forced strengthening process were obtained, respectively and compared. The difference of the load-deflection characteristic was conducted. For understanding and explaining this difference, two known mechanisms for the forced strengthening process on the load-deflection characteristic of the spring, namely the geometry change of the spring structure and residual stress effects, were introduced and studied. The results show that although two mechanisms have both attribute to this change of the characteristic of the spring after forced strengthening process, the geometry-related mechanism plays a more important role as a main mechanism and the height change of the spring is the main factor among these geometry changes in geometry-related mechanism.
\end{abstract}

Index Terms-Diaphragm spring, forced strengthening, load-deflection characteristic, residual stress, mechanism.

\section{INTROD1UCTION}

Diaphragm spring is well known for its configuration to nonlinearly withstand a large force with minimum deflection while storing a large amount of energy in relation to the occupied space. The nonlinear load-deflection $(\mathrm{P}-\mathrm{d})$ characteristic is one of the most importance characteristics of the diaphragm spring for industry application [1]. In most case, the nonlinear load-deflection characteristic of the diaphragm spring will change during its operation. Once the load-deflection characteristic of the spring changes greatly, such as the peak clamp load decreases sharply, it will lead to some failures such as slipping, burning and high temperature which directly affects the operation life of the diaphragm spring related part. In automobile clutch application, such failure phenomenon of load-deflection characteristic decreasing is named as elastic extenuation of the spring.

Manuscript received June 8, 2016; revised August 23, 2016. This work was supported in part by the Education Department of Guangxi Autonomous Region P.R. China under Grant LD14065B

The authors are with School of Mechanical and Electrical Engineering, Guilin University of electronic technology, Guilin, CO 541004 China (e-mail: gybcome@gmail.com,gybcome@guet.edu.cn).
Many researches have been done on how to precisely predict the nonlinear $\mathrm{P}-\mathrm{d}$ curve for each spring. Almen and Laszlo [2] developed a theory and derived a simple formula becoming the current standard. Recently, Zheng E [3] obtained a new analytical solution of the load deflection characteristic of the Belleville springs through energy method and Kobelev V [4] developed a closed form analytical solutions based on the common deformation hypotheses for the equations of thin- and thick-walled truncated conical disc springs with rectangular cross-section. By taking the finger part and other local structures such as rounder corner in the inner radius of the spring into consideration, the finite element method was applied to the diaphragm spring modeling and the corresponding load-deflection characteristic was obtained [5]-[7]. Patangtalo, W. etc [8] used the Rayleigh-Ritz approach and finite element method to obtain the load-deflection characteristic of the woven fiber-reinforced composite Belleville springs.

The Strengthening process including shot-peening and forced strengthening are commonly implemented during the manufacturing process to improve the performance and fatigue life of the diaphragm springs [9]. Basically, single-side or double-side shot peening process can greatly improve the fatigue life of the diaphragm spring by introducing much compression stress and the forced strengthening process can stabilize the load-deflection characteristic of the diaphragm spring by accelerating the elastic extenuation of the spring. It is also found that the strengthening process has a remarkable effect on the load-deflection characteristic of the diaphragm spring. Yasunori Doman [10] revealed that residual stress induced by the shot-peening process alters the free height of the springs, thus changes the characteristic of the spring. They also pointed out the free height change is not enough to explain the total effect of shot-peening on the $\mathrm{P}-\mathrm{d}$ curve of diaphragm springs and tried to explain it in terms of the effect of residual stress on the stiffness matrix. Zhang tieshan [11], [12] etc investigated the residual stress in the spring after the shot-peening and forced strengthening process by X-ray stress analyzer and experimentally inferred the residual stress and change of local material characteristic are main factors affecting load-deflection characteristic.

Among these previous researches, the mechanism of the forced strengthening on the load-deflection characteristic is remained to be completely understood. In other words, it is not well known why and how forced strengthening affects the load deflection characteristic of the diaphragm springs. The objective of this research is to show how the forced strengthening affects the nonlinear response of diaphragm 
springs. Then, the mechanism of the forced strengthening on the load-deflection characteristic was revealed by using the finite element method.

\section{FINITE ELEMENT SimULATION}

\section{A. Moldeling}

In the simulation, the outer radius $\mathrm{R}$ and inner radius $\mathrm{r}$ of the specific diaphragm spring are 430/2 $\mathrm{mm}$ and 395/2 $\mathrm{mm}$. The inner contact position 1 is $308 \mathrm{~mm}$ and the outer contact position $\mathrm{L}$ is $391 \mathrm{~mm}$. The whole diaphragm spring made of the materials $51 \mathrm{CrV} 4$ is consisted of 24 finger parts shown as Fig. 1. For improving the computational efficiency, according the symmetry of the structure, 1/24 finite element model was built shown as Fig. 2 and Fig. 3. For these two finite element model, the 3-D 20-node solid element was applied to mesh the geometry. The difference of the two model is the numbers of the node and the size of the element. In Fig. 2, the coarse mesh model was applied with 31072 nodes and 6493 elements of about $2 \mathrm{~mm}$ size. In Fig. 3, the fine mesh model was applied with 113701 nodes and 25623 elements of about $1 \mathrm{~mm}$ size. The reason of studying the two models is to find an effective model which comprises the efficiency and accuracy in finite element simulation for the spring .

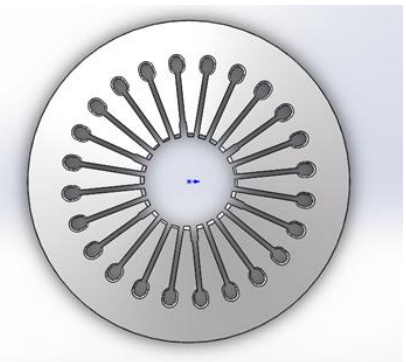

Fig. 1. Geometry structure of the spring.

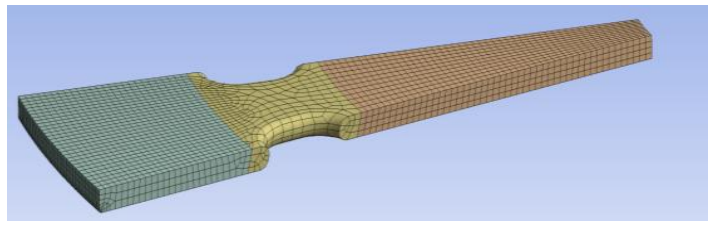

Fig. 2. Coarse mesh model.

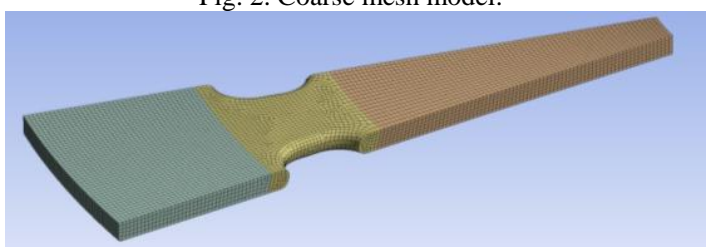

Fig. 3. Fine mesh model.

\section{B. Boundary Conditions}

The load deflection measurement equipment for the diaphragm spring is shown as Fig. 4. During the measurement, the diaphragm spring is put on the bottom supporting plate and the upper mold of the holly cylinder moves top-down to push the spring. Meanwhile the displacement sensor and force sensor records the corresponding displacement and force of the upper mold. The upper mold contacts the diaphragm spring at the inner contact position 1 of the spring and the bottom plate contact the diaphragm spring at the outer contact position $\mathrm{L}$ of the spring.

The forced strengthening equipment of the diaphragm spring is shown as Fig. 5. During the process, the reverse-state diaphragm spring is put on the bottom mold of a holly cylinder and the upper mold of the plate moves top-down to push the spring. Reversely, the upper plate contact the diaphragm spring at the outer contact position $\mathrm{L}$ of the spring and the bottom mold contacts the diaphragm spring at the inner contact position 1 of the spring.

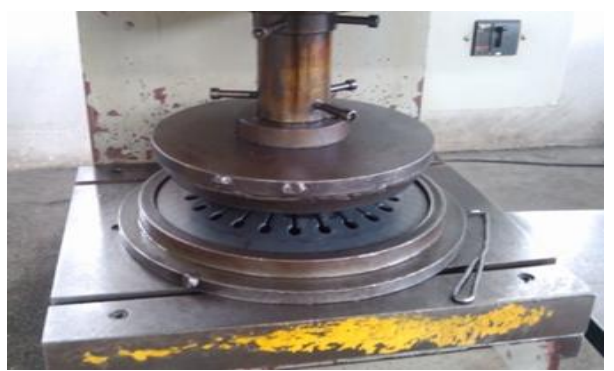

Fig. 4. Load deflection measurement equipment.

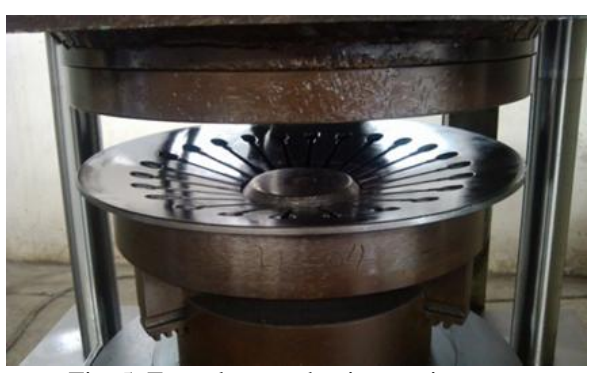

Fig. 5. Forced strengthening equipment.

Although there exits some friction between the spring and the upper \& bottom mold, these friction force is hard to be determined and seems not to have much influence on the change of the load deflection characteristic of the spring after the forced strengthening process in engineering. Thus, in our simulation these friction force was neglected and the upper mold and bottom mold was not modeled directly. The force and constraints between spring and the upper \& bottom mold was applied at their contact area, namely the inner contact position and the outer contact position of the spring shown in Fig. 6 and Fig. 7. For the load deflection characteristic measurement, the outer contact position of the spring is fixed along the axial direction and the specific displacement (10mm) along the axial direction is assumed at the inner contact position. For the forced strengthening, reversely, the inner contact position of the spring is fixed along the axial direction and the specific displacement $(8.5 \mathrm{~mm})$ along the axial direction is assumed at the outer contact position.

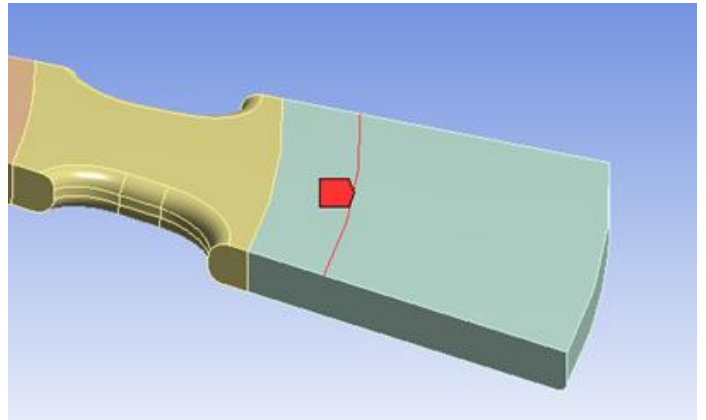

Fig. 6. Inner contact position of the spring 


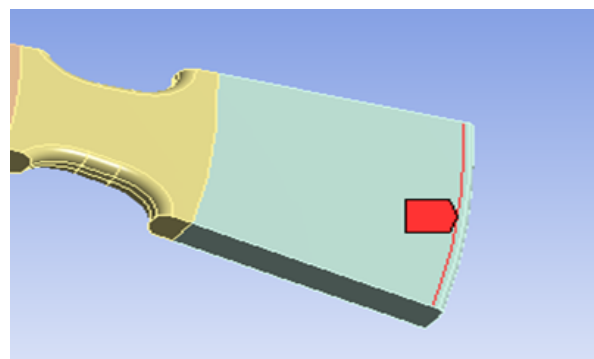

Fig. 7. Outer contact position of the spring.

\section{Model Verification}

The load deflection value of the spring based on the coarse mesh model and fine mesh model at several selected points is shown in table 1 . It can be seen from table 1 that the peak clamp load and valley clamp load of the coarse mesh is almost the same with that of the fine mesh model. That is to say, the result of the coarse model is converged. The comparison between the finite element simulation and the A-L formula's analytical result was also shown in the table 1 and Fig. 8. It can be seen from the table 1 and Fig. 8 that the finite element simulation and the A-L formula's result have a same trend generally. When the displacement of the spring is relative small $(<5 \mathrm{~mm}$, namely around the peak force value $)$, the difference between the finite element simulation and the A- $\mathrm{L}$ formula's analytical result is much less (the relative error is less than 3.8\%), and when the displacement grows bigger $(>6 \mathrm{~mm}$, namely around the valley force value ), the difference between them is obvious (the relative error is about $11.0 \%$ ) and the force value by A-L formula is bigger than that by the finite element simulation within this range. It was reported that the valley force value of the load deflection characteristic of the spring by A-L formula is relatively larger than its test value ${ }^{[1]}[10,11]$. Take the above facts into accounting, the finite simulation is valued and for improving the computational efficient, we used the coarse mesh model for the following simulation.

TABLE I: LOAD DEFLECTION CHARACTERISTIC OF THE SPRING BASED ON THE COARSE MODEL, FINE MESH MODEL AND A-L FORMULA

\begin{tabular}{|l|l|l|l|}
\hline & $\begin{array}{l}\text { Force(N) } \\
\text { coarse mesh } \\
\text { model }\end{array}$ & $\begin{array}{l}\text { fine mesh } \\
\text { model }\end{array}$ & A-L formula \\
\hline 0 & 0 & 0 & 0 \\
\hline 1 & 19833.84 & 19837.68 & 19150 \\
\hline 2 & 31365.6 & 31372.8 & 30770 \\
\hline 3.5 & 37132.8 & 37144.8 & 37430 \\
\hline 5 & 34312.8 & 34310.4 & 35690 \\
\hline 6 & 30540 & 30542.4 & 34210 \\
\hline 7 & 26973.6 & 26976.0 & 29210 \\
\hline 8.5 & 24811.2 & 24801.6 & 27860 \\
\hline 10 & 30007.2 & 29980.8 & 35220 \\
\hline
\end{tabular}

\section{RESPONSE OF THE FORCED STRENGTHENING PROCESS}

In our finite simulation for the forced strengthening process, three load steps were set up. The first and second load step are outward trip and return trip with the displacement $8 \mathrm{~mm}$ on the inner contact position of the spring, respectively. The third load step is a free condition without any external load and constraints in the spring in order to study the residual deformation, stress and strain of the spring after forced strengthening. The whole load step setting is shown in the Table II.

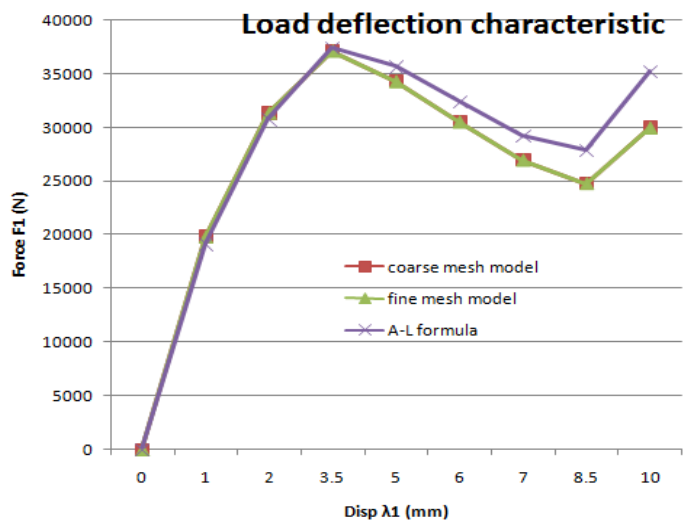

Fig. 8. Load deflection characteristic curve based on the coarse model, fine mesh model and A-L formula.

TABLE II: LOAD STEP SETTING FOR THE FORCED STRENGTHENING

\begin{tabular}{|c|c|}
\multicolumn{2}{|c|}{ PROCESS } \\
\hline Load step number & Displacement $/ \mathrm{mm}$ \\
\hline 0 & 0 \\
\hline 1 & 8 \\
\hline 2 & 0 \\
\hline 3 & N/A \\
\hline
\end{tabular}

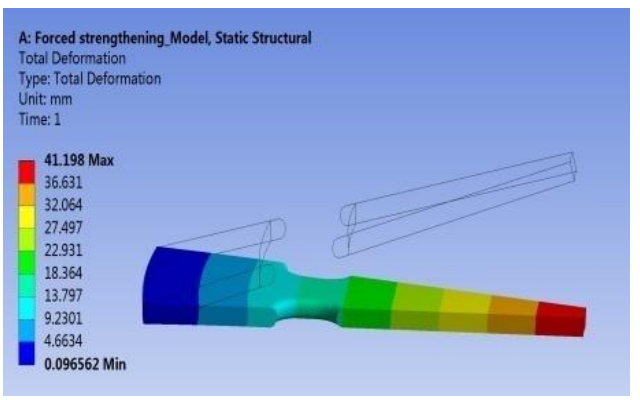

(a) end of the outward trip.

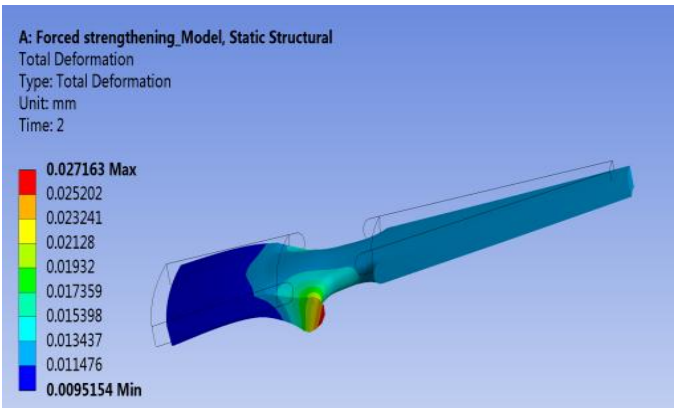

(b) end of return trip

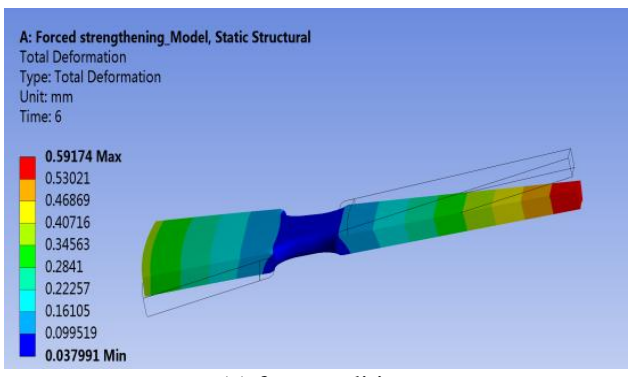

(c) free condition

Fig. 9. Total deformation of the spring during the process at (a) end of the outward trip, (b)end of return trip and (c)free condition. 
The total deformation of the spring at the first, second and third load step were shown in Fig. 9, respectively. In Fig.s 9, the wireframe indicates the original location of the spring and the contours indicates the current location of the spring. It can be seen from the three Fig.s that as the forced strengthening proceeds, the deformation of the spring varies correspondingly, and eventually the spring comes up a residual deformation which results in a rotating of the spring. The maximum total residual deformation occurs in the inner end of the spring, which is $0.59 \mathrm{~mm}$ probably enough to obviously influence the load deflection characteristic of the spring.

The equivalent stress of the spring at different load step is shown in the Fig. 10, respectively. From the Fig. 10 it can be seen that at the end of the outward trip the maximum equivalent stress $1227 \mathrm{MPa}$ occurs in the inner radius area of the diaphragm spring, namely the I point. Around the outer radius area namely the III point exits relative much equivalent stress. These are in accord with the analytical result by the A-L formula. After the return trip the inner radius area comes up much equivalent stress (as Fig. $11 \mathrm{~b}$ ) and consequently exits much residual stress (as Fig. $11 \mathrm{c}$ ). It is worth to note that after the three load steps the residual stress exit only around the inner radius area.

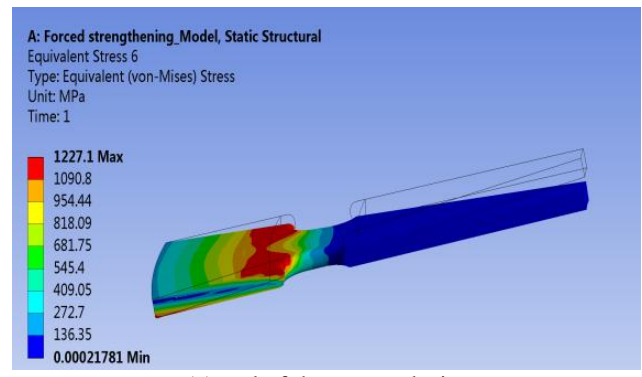

(a) end of the outward trip.

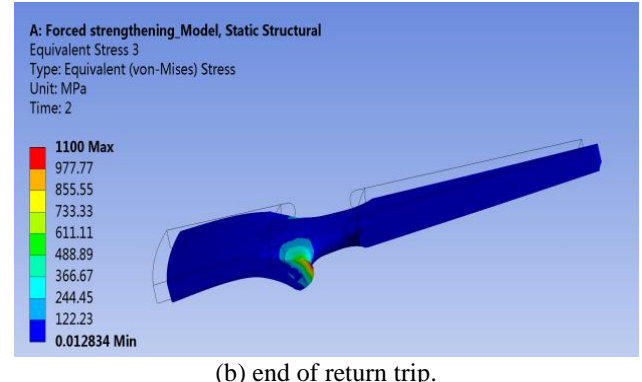

(b) end of return trip.

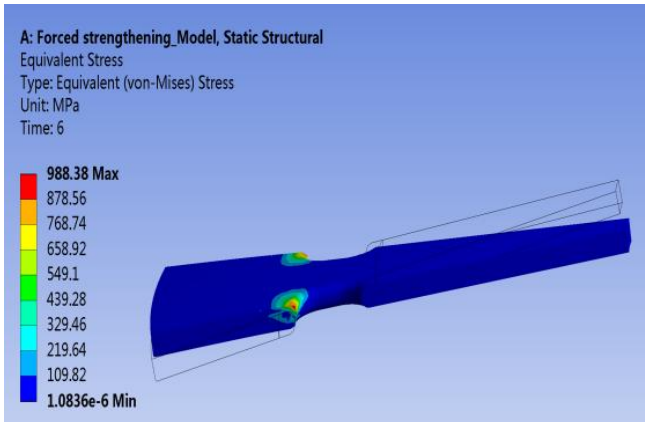

(c) free condition

Fig. 10. Equivalent stress of the spring during the process at (a) end of the outward trip,( b)end of return trip and (c)free condition.

The equivalent plastic strain of the spring at different load step is shown in the Fig. 11, respectively. It can be seen that only around the inner radius of the spring occurs plastic strain at all the end of three load step.

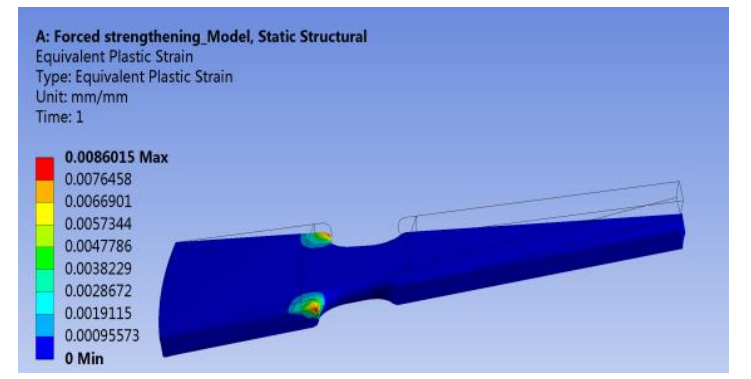

(a) end of the outward trip

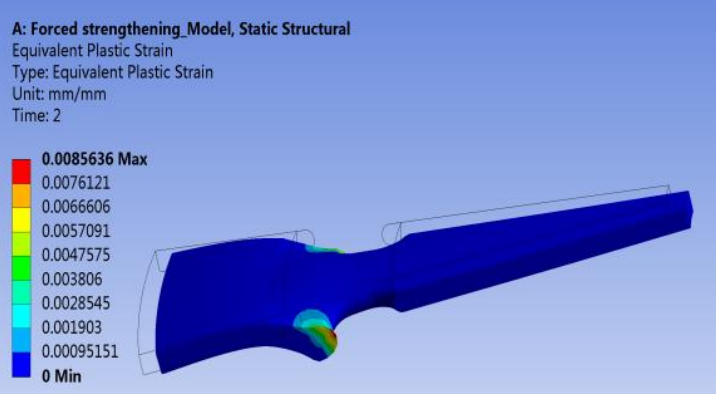

(b) end of return trip

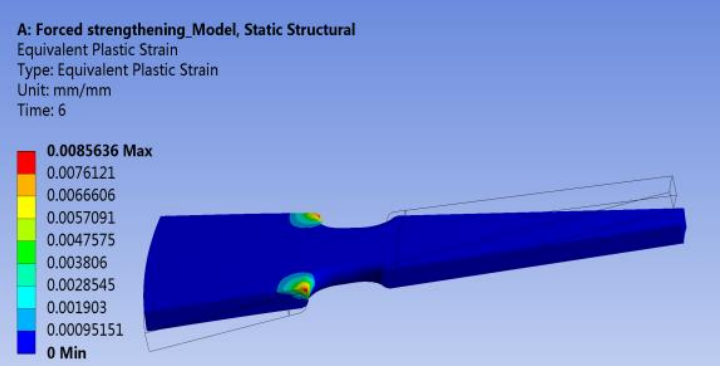

(c) free condition

Fig. 11. Equivalent plastic strain of the spring during the process at (a) end of the outward trip, ( b)end of return trip and (c)free condition

\section{Mechanism of the Forced Strengthening Process}

\section{A. Geometry Related Mechanism and Stress Related Mechanism}

The load deflection characteristic of the spring before and after the forced strengthening process was shown in Fig. 12, respectively. It can be seen from the Fig. 12 that the peak force value decreases greatly after the forced strengthening process from the original $37132.8 \mathrm{~N}$ to $34908 \mathrm{~N}$ and the valley force value doesn't change obviously.

It is known that there are two probable mechanisms accounting for the influence of the strengthening process on the load deflection characteristic of the spring. One is the residual stress related mechanism [1], [9]. The residual stress of the spring induced by the strengthening might change the assembly stiff matrix of the structure, then change the response of the spring under the external load. The other is the geometry deformation related mechanism [1], [10], [11]. During the strengthening process the spring undergoes much stress over the elastic limit strength of the material, which results in the plastic strain and residual deformation of the spring. However for the forced strengthening process, the dominated mechanism is still unknown. For understanding it better, two individual models according to the two mechanisms are built up to estimate their own influence 
model I only considers the residual equivalent stress and residual plastic strain by the forced strengthening, which is according to the stress-related mechanism. And the other model named model II only take the residual deformation by the forced strengthening into account, which is according to the geometry related mechanism. After finishing the simulation of the forced strengthening process, the corresponding residual equivalent stress and residual plastic strain is derived and transferred into an model to built the model I through the APDL (ANSYS Parameter Design Language) command of the ANSYS software. The plastic strain distribution of the mode II at the initiated and ending condition is shown in Fig. 13. At the initiation condition, the plastic strain of the mode $I$ is same as the residual plastic strain of the model after the forced strengthening. The plastic strain grows up as the displacement of the outer ending of the spring increases.

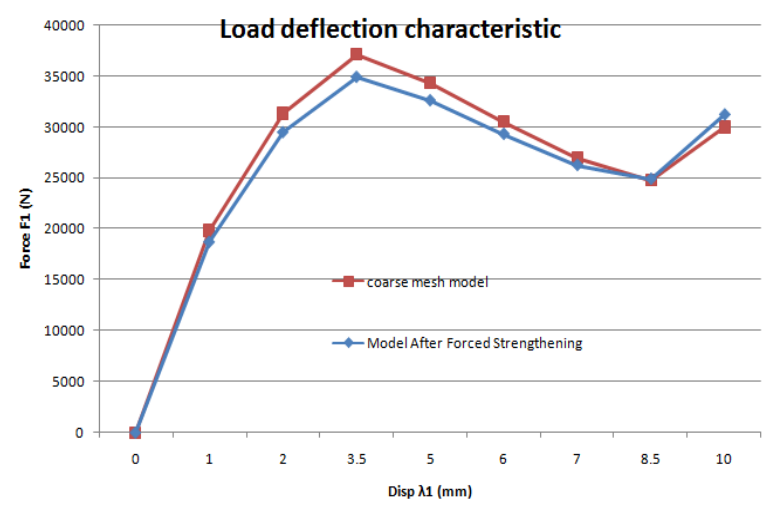

Fig. 12. Load deflection characteristic of the spring before and after the forced strengthening process

Similarly, the corresponding geometry deformation by the forced strengthening is derived and transferred to another model to form the model II.

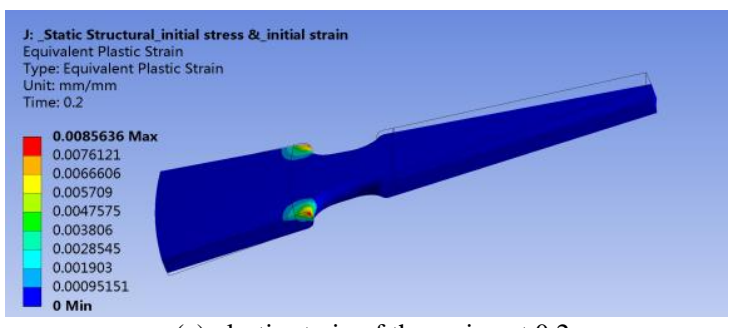

(a) plastic strain of the spring at $0.2 \mathrm{~s}$

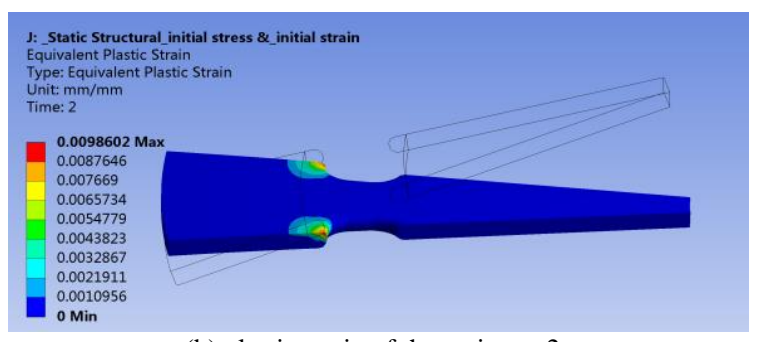

(b) plastic strain of the spring at $2 \mathrm{~s}$

Fig. 13. Equivalent plastic of the spring at (a)0.2s and (b)2s.

The load deflection characteristic of the spring based on the model I and the model II was shown in table 3 and Fig. 14. From table 3 and Fig. 14 it can be seen that the characteristic based on the model I is close to that based on the coarse mesh model before the forced strengthening, and the characteristic based on the mode II is close to that based on the model after forced strengthening. It means that only considering the change of the residual stress the load deflection characteristic of the spring varied unobvious, and only considering the change of the geometry deformation mainly account for the difference of the load deflection characteristic of the spring after the forced strengthening process. The simulation result indicates that for the forced strengthening process the geometry-related mechanism plays a dominated role in influencing the load deflection characteristic of the spring.

TABLE III: LOAD DEFLECTION CHARACTERISTIC OF THE SPRING BEFORE AND AFTER THE FORCED STRENGTHENING PROCESS BASED ON DIFFERENT MODEL

\begin{tabular}{|c|l|l|l|l|}
\hline Force(N) & $\begin{array}{l}\text { Model } \\
\text { coarse } \\
\text { mesh } \\
\text { model } \\
\text { After } \\
\text { Fisp(mm) }\end{array}$ & $\begin{array}{l}\text { Forced } \\
\text { Strength- } \\
\text { ening }\end{array}$ & Model I & Model II \\
\hline 0 & 0 & 0 & 0 & 0 \\
\hline 1 & 19833.8 & 18711.1 & 19771.6 & 18789.84 \\
\hline 2 & 31365.6 & 29484 & 31233.6 & 29630.4 \\
\hline 3.5 & 37132.8 & 34908 & 37101.6 & 35006.4 \\
\hline 5 & 34312.8 & 32616 & 34627.2 & 32440.8 \\
\hline 6 & 30540 & 29323.2 & 30885.6 & 29133.6 \\
\hline 7 & 26973.6 & 26270.4 & 27148.8 & 26193.6 \\
\hline 8.5 & 24811.2 & 24921.6 & 24376.8 & 25423.2 \\
\hline 10 & 30007.2 & 31226.4 & 28963.2 & 32361.6 \\
\hline
\end{tabular}

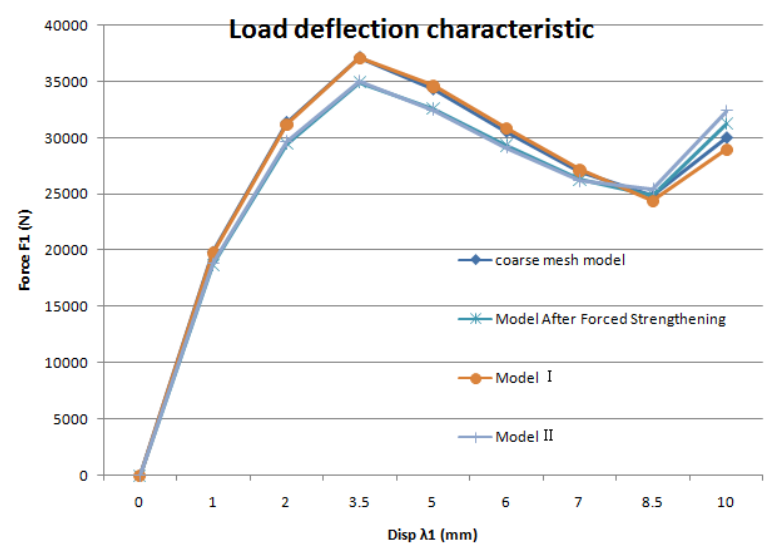

Fig. 14. Load deflection characteristic of the spring before and after the forced strengthening process based on different model.

\section{B. Height Decrease of the Spring}

After the forced strengthening, the residual deformations of the spring in radial direction and axial direction are shown in Fig. 15. It can be seen from Fig. 14a that the distance of outer ending of the spring to the axial line of the spring, normally named by $\mathrm{R}$, increases by $0.04 \mathrm{~mm}$ (namely $\Delta \mathrm{R} \sim 0.04 \mathrm{~mm}$ ) and the distance of the inner ending of the spring to the axial line of the spring, namely named by $\mathrm{r}$, decrease by $-0.06 \mathrm{~mm}$ (namely $\Delta \mathrm{r} \sim 0.06 \mathrm{~mm}$ ). With these changing range of the $\mathrm{R}$ and the $\mathrm{r}$, it is found that it has no obvious influence on the load deflection characteristic of the spring by applying the A-L formula.

It can be seen from Fig. 14b and Fig. 14a that the deformation in the axial direction is the main part of the total deformation of the spring. The height of the outer ending of the spring increases by about $0.36 \mathrm{~mm}$ and the height of the inner ending of the spring increases by about $0.10 \mathrm{~mm}$. 
Therefore, the height of the spring decreases by about $0.26 \mathrm{~mm}$ after the forced strengthening process. Because of the load deflection characteristic of the spring is prone to the height change of the spring, it is found that $0.26 \mathrm{~mm}$ height change will decrease the peak force value from the $37585.6 \mathrm{~N}$ to $35674.7 \mathrm{~N}$ by the A-L formula. In other words the $0.26 \mathrm{~mm}$ height change leads to about $1910 \mathrm{~N}$ decreasing in the peak force value. In our finite simulation, after the forced strengthening process, the peak force value decreases from the $37132.8 \mathrm{~N}$ to $34908 \mathrm{~N}$ shown in the table 2 , namely about $2200 \mathrm{~N}$ decreasing in the peak force value, which is close to that above by the A-L formula. It proves that the height change of the spring after the forced strengthening is the main factor influencing the load deflection characteristic of the spring.

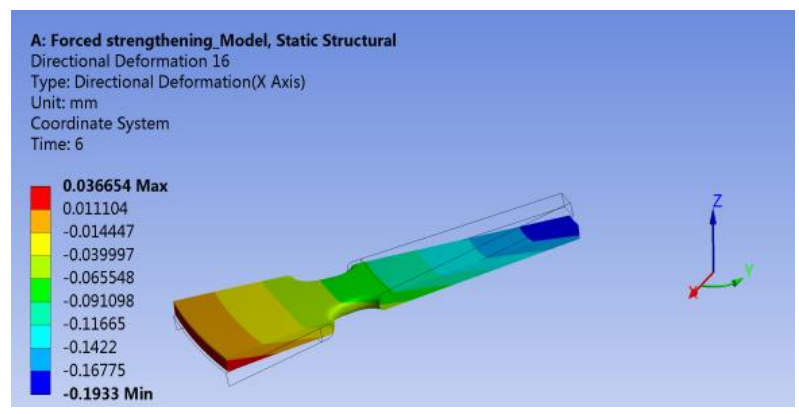

(a) residual deformation in radial direction

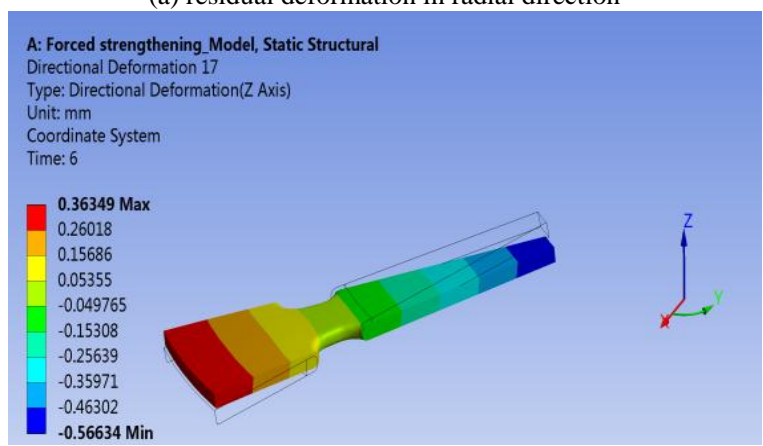

(b) residual deformation in axial direction

Fig. 15. Residual deformation of the spring in the (a) radial direction and (b) in the axial direction.

\section{CONCLUSIONS}

In this paper the simplified finite element model of spring for the load deflection measurement process and forced strengthening process is built and verified. Based on the simplified model the deformation, equivalent stress and equivalent strain during the forced strengthening were obtained. The load deflection characteristic of the diaphragm before and after the forced strengthening was compared. It is found that after the forced strengthening process the peak force value of the spring decreases obviously. According to the stress related mechanism and geometry related mechanism, the residual stress, plastic strain and deformation after the forced strengthening process were derived and transferred into specific model to produce two corresponding mechanism model. The simulations and comparison show that the geometry related mechanism is the dominated mechanism for the forced strengthening process influencing the load deflection characteristic of the spring. The change of the spring structure in the radial direction and axial direction was examined and found that the height change of the spring is the main factor which eventually influencing the load deflection characteristic of the spring after the forced strengthening process.

\section{REFERENCES}

[1] L. Shi-Yu. "Diaphragm spring and Belleville spring clutches design and manufacturing," Nanjing: Southeast University Press, 1995, ch 2 ,pp 25-27. (In Chinese)

[2] J. O. Almen and A. Laszlo, "The uniform-section disk spring," Trans. ASME, vol. 58, no. 4, pp. 305-314, 1936.

[3] E. Zheng, F. Jia, and X. Zhou, "Energy-based method for nonlinear characteristics analysis of Belleville springs," Thin-Walled Structures, vol. 79, pp.52-61, June 2014.

[4] V. Kobelev "Exact shell solutions for conical springs," Mechanics Based Design of Structures and Machines, pp. 1-23, July 2015.

[5] L. En, G. L. iangjin, and F. Z. ijie, "Finite element analysis of the mechanics characteristics of diaphragm spring," Automotive Engineering, no.10 ,pp. 892-896, 2010.

[6] J. Yang and T. Zhang, "Fingers structure's effect on load-deformation characteristic for diaphragm spring," Tractor and Farm Transporter, no. 2, pp.7, 2011.

[7] W. Nam, C. Lee, and J. Kwon, "Finite element analysis and optimal design of automobile clutch diaphragm spring," Seoul 2000 FISITA World Automotive Congress, pp. 1-5, Seoul, Korea, June 2000.

[8] W. Patangtalo, M. W. Hyer, and S. Aimmanee, "On the non-axisymmetric behavior of quasi-isotropic woven fiber-reinforced composite Belleville springs," Journal of Reinforced Plastics and Composites, pp. 1-11, Nov 2015.

[9] Z. Yan, G. Tu, and M. Liu, "Optimization of material and strengthening process in design for performance of elastic elements," Materials Research Innovations, vol. 19, pp. S5-S769, 2015.

[10] Y. Doman, T. Fujii, K. Okubo et al., "Influence of residual stress on the load - deflection curve of diaphragm springs for automobile clutches," JSAE Review, vol. 24, no. 2, pp. 197-203, 2003.

[11] T. S. Zhang and N. L. Tian, "A study on strengthened processing affecting the load deformation properties of diaphragm spring," Automobile Technology, no. 4, pp. 58-61, 2012.

[12] Q. F. Ma, T. S. Zhang, H. Jing, and J. S. Wu, "A study on strengthened processing affecting the load deformation properties of diaphragm spring," Automobile Technology and Material, no. 12, pp. 6-10, 2013)

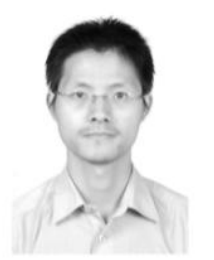

Gong Yubing was born in Hubei province, China and he received his BSc., MSc., in mechanical engineering from the Guilin University of Electronic Technology, Guangxi Province, China, in 2001 and 2004, respectively. He received his Ph.D. in astronomical techniques and methods from the National Astronomical Observatories of the Chinese Academy of Sciences (NAOC), Beijing, China, in 2010.

Currently, he is a associate professor at the school of mechanical and electrical engineering, Guilin University of electronic technology, Guangxi province, China. His current research interests include structural design and design optimization, numerical simulation, numerical dynamic. He has over 20 publications in international scientific journals and conferences.

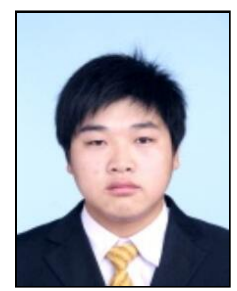

Zhang Defeng was born in Henan province, China, in April 1990. He is now a master degree candidate in the school of mechanical and electrical engineering at the Guilin University of electronic technology, Guangxi province, China. His main research interest is structural analysis. 